\title{
Phenotyping of rice in salt stress environment using high-throughput infrared imaging
}

\author{
Zamin S. Siddiqui ${ }^{2 *}$, Jung-Il Cho ${ }^{1}$, Sung-Han PARK ${ }^{1}$, TAeK-Ryoun Kwon ${ }^{1}$, \\ Byung-OK AhN ${ }^{1}$, GAng-Seob LeE ${ }^{1}$, Mi-JeOng JeOng ${ }^{1}$, Kyung-Whan Kim ${ }^{1}$, \\ SEONG-Kon LEE ${ }^{1}$, SoO-CHUL PARK ${ }^{1}$ \\ ${ }^{1}$ National Academy of Agricultural Sciences, Rural Development Administration, \\ Suwon 441-707, Republic of Korea \\ ${ }^{2}$ Stress and Crop Physiology Laboratory, Department of Botany, University of Karachi, \\ Karachi 75270, Pakistan
}

\begin{abstract}
Phenotyping of rice (Oryza sativa L. cv. Donggin) in salt stress environment using infrared imaging was conducted. Results were correlated with the most frequently used physiological parameters such as stomatal conductance, relative water content and photosynthetic parameters. It was observed that stomatal conductance $\left(R^{2}=-0.618\right)$ and relative water content $\left(\mathrm{R}^{2}=-0.852\right)$ were significantly negatively correlated with average plant temperature (thermal images), while dark-adapted quantum yield $\left(\mathrm{F}_{\mathrm{v}} / \mathrm{F}_{\mathrm{m}}, \mathrm{R}^{2}=\right.$ $-0.325)$ and performance index $\left(\mathrm{R}^{2}=-0.315\right)$ were not consistent with plant temperature. Advantages of infrared thermography and utilization of this technology for the selection of stress tolerance physiotypes are discussed in detail.
\end{abstract}

Keywords: Infrared imaging, phenotype, rice, salt stress

\section{Introduction}

Plants of the same genotype may have different phenotypes, depending on the growing environment. Phenotyping is a technique dealing with plant visible characteristics (phenotypes), or trait analysis. Conventional phenotyping has been hard, time consuming and destructive. Recent development of high-tech imaging systems and their computation enables modern, fast and non-destructive phenotyping research. Depending on the plant traits, high-throughput phenotyping techniques can be useful because they can reduce phenotyping time from weeks to minutes, or even seconds. High technology in phenomics accelerates the procedure for selecting plant varieties that perform better in the field when affected by drought or salt. In the past, physiological attributes like stomatal conductance, osmotic potential, dark-adapted quantum yield and biomass allocation were frequently used in phenotyping techniques under salt and drought stress environments (DAVIS et al. 2005, BURKE

\footnotetext{
* Corresponding author, e-mail: usdapark@korea.kr

Copyright $^{\circledR} 2014$ by Acta Botanica Croatica, the Faculty of Science, University of Zagreb. All rights reserved.
} 
et al. 2006, SidDiQui et al. 2008, MunNs et al. 2010, RichARdS et al. 2010, SidDiQui 2013). However, these physiological attributes were time consuming, laborious, and destructive. More common physiological approaches and modern high-tech infrared phenotyping techniques are being used to identify stress tolerant plants. Therefore, it is important to correlate the two techniques and to standardize the protocol for testing favourable phenotypes under salt stress environment (MunNs et al. 2010). Although literature showing phenotyping using an infrared (IR) camera is available, these techniques need to be closely monitored and should be correlated with physiological data that might have some role in the regulation of plant temperature in abiotic stress environment (MERLOT et al. 2002, JONES et al. 2009, ColLins et al. 2010). Mainly, high-tech phenotyping through an IR camera is based on the temperature/heat produced in stress-plant (MunNS et al. 2010). Therefore, the present study has been designed to examine the phenotyping of rice cv. Donggin by highly sensitive IR thermal camera and find out its correlation with some physiological parameters in salt stress environment. Stomatal regulation and plant water status are important aspects in stress environment and these physiological attributes stabilize the temperature inside the plant leaf. The hypothesis that physiological parameters related to plant temperature are affected by the salt stress was tested using infrared imaging.

\section{Material and methods}

\section{Germination and growth}

Seeds of rice (Oryza sativa L. cv. Donggin) were collected from National Center for Genetically Modified Crops, National Academy of Agricultural Science, Rural Development Administration, South Korea. Seeds were washed with distilled water several times before sowing, then allowed to germinate in $90 \mathrm{~mm}$ diameter Petri dishes. Six-day old equal size seedlings were transferred to a hydroponic system. After transplanting, the seedlings were left for a further four days in half-strength Yoshida nutrient solution prior to the imposition of $\mathrm{NaCl}$ (Tab. 1). Plants were treated with 75,150 and $225 \mathrm{mM} \mathrm{NaCl}$ in full-strength

Tab. 1. Yoshida solution composition.

\begin{tabular}{lc}
\hline Chemical & Amount $(\mathrm{g} / 5 \mathrm{~L})$ \\
\hline $\mathrm{NH}_{4} \mathrm{NO}_{3}$ & 475 \\
$\mathrm{NaH}_{2} \mathrm{PO}_{4} \times \mathrm{H}_{2} \mathrm{O}$ & 201 \\
$\mathrm{~K}_{2} \mathrm{SO}_{4}$ & 357 \\
$\mathrm{CaCl}_{2}$ & 443 \\
$\mathrm{MgSO}_{4} \times 7 \mathrm{H}_{2} \mathrm{O}$ & 1620 \\
\hline $\mathrm{MnCl}_{2} \times 4 \mathrm{H}_{2} \mathrm{O}$ & 7.50 \\
$\left(\mathrm{NH}_{4}\right)_{6} \mathrm{Mo}_{7} \mathrm{O}_{24} \times 4 \mathrm{H}_{2} \mathrm{O}$ & 0.37 \\
$\mathrm{H}_{3} \mathrm{BO}_{3}$ & 4.67 \\
$\mathrm{ZnSO}_{4} \times 7 \mathrm{H}_{2} \mathrm{O}$ & 0.18 \\
$\mathrm{CuSO}_{4} \times 5 \mathrm{H}_{2} \mathrm{O}$ & 0.16 \\
\hline $\mathrm{FeCl}_{3} \times 6 \mathrm{H}_{2} \mathrm{O}$ & 38.5 \\
$\mathrm{C}_{6} \mathrm{H}_{8} \mathrm{O}_{7} \times \mathrm{H}_{2} \mathrm{O}$ & 59.5 \\
\hline $1 \mathrm{M} \mathrm{H}_{2} \mathrm{SO}_{4}$ & $250 \mathrm{~mL}$ \\
\hline
\end{tabular}


Yoshida nutrient solution, while control plants were treated with only Yoshida solution. Treated and control plants were grown in a growth chamber (EYELA) at a temperature of $25-28 \pm 2{ }^{\circ} \mathrm{C}, 60-80 \%$ humidity and a photoperiod of $14 / 10$ hours (day/night). Light intensity varied from $200-350 \mu \mathrm{mol}$ photon $\mathrm{m}^{-2} \mathrm{~s}^{-1}$. Experiments were replicated four times.

\section{Relative water content}

Six randomly selected leaves from each treatment and control were sampled and $4 \times 2$ $\mathrm{cm}^{2}$ mid-vein and the edge sections were cut with scissors. After fresh weight measurement, each sample was placed in a $90 \mathrm{~mm}$ air-tight plastic Petri plate containing distilled water. After 12-hours hydration in the dark, the leaf samples were taken out of the water and their surfaces were well dried quickly and lightly with filter/tissue paper and immediately weighed to obtain fully turgid weight (TW). Leaf samples were then oven dried at $80^{\circ} \mathrm{C}$ for $24 \mathrm{~h}$ and weighed to determine dry weight (DW). Relative water content (RWC) was calculated using the following formula:

$$
\operatorname{RWC}(\%)=[(\mathrm{FW}-\mathrm{DW}) /(\mathrm{TW}-\mathrm{DW})] \times 100
$$

where FW is sample fresh weight, TW is sample turgid weight, and DW is sample dry weight.

\section{Stomatal conductance and PSII quantum yield}

Stomatal conductance of twenty randomly selected leaves of each treatment and control were examined using a leaf porometer (Model SC-1, Decagon, USA). Measurements of chlorophyll $a$ fluorescence emissions from the twenty randomly selected leaves were monitored with a fluorescence monitoring system (Company Handy PEA) in the pulse amplitude modulation mode. A leaf adapted to dark conditions for 30 minutes using leaf-clips was initially exposed to a modulated measuring beam of far-red light (LED source with a typical peak at wavelength $735 \mathrm{~nm})$. Original $\left(\mathrm{F}_{0}\right)$ and maximum $\left(\mathrm{F}_{\mathrm{m}}\right)$ fluorescence yields were measured under weak modulated red light $\left(<0.5 \mu \mathrm{mol} \mathrm{m}^{-2} \mathrm{~s}^{-1}\right)$ with $1.6 \mathrm{~s}$ pulses of saturating light $\left(>6.8 \mu \mathrm{mol} \mathrm{m}^{-2} \mathrm{~s}^{-1}\right.$, photosynthetically active radiation). The variable fluorescence yield $\left(F_{v}\right)$ was calculated by the equation of $F_{m}-F_{0}$. The ratio of variable to maximum fluorescence $\left(\mathrm{F}_{\mathrm{v}} / \mathrm{F}_{\mathrm{m}}\right)$, calculated as maximum quantum yield of PSII photochemistry as well as photosynthesis performance index were determined as described by MAXWELL and JOHNSON (2000).

\section{IR thermal images}

We used FLIR-SC-620 (FLIR Systems, USA) for thermal imaging experiments. The system was optimized 30 minutes before measurements. To test the temperature difference between treated and untreated plants in salt stress environment, plants of each treatment and control were examined. Plant images were taken using a rectangular box of an area about 46 $\times 30 \mathrm{~cm}^{2}$. Temperature of $24 \pm 2{ }^{\circ} \mathrm{C}$ inside the box and relative humidity of $60-70 \%$ were recorded. The images were taken at 10 a.m. using a FLIR SC-620 series camera with $640 \times$ 480 pixel IR resolution. Images from each treatment and control were directly extracted from the camera into computer and a report was generated using ThermaCAM Researcher Pro 2.10 software. 


\section{Statistical analysis}

All data from treated and control plants were subjected to analysis of variance using SPSS 17.0 software. The values were expressed as the mean of four replicates \pm standard error $(\mathrm{SE})$. Student t-test $(\mathrm{p}<0.05)$ was used to check statistical significance. Correlation analysis was computed between average plant temperatures (IR image) and physiological attributes.

\section{Results}

Infrared thermography phenotyping technique was used to identify plant response in salt stress environment showing significant difference between salt stress and unstressed plants (Fig. 1). For this study, plants were subjected to various salt concentrations and therefore plant temperatures and color patterns were recorded. Image colors represent the temperature pattern and were in the following order: blue (less temperature) < green $<$ yellow $<$ red (high temperature). Plants in a saline environment showed substantially less blue color expression than those in a non-saline environment. It was observed that blue color intensity changed from blue to green, then yellow and red color as salinity increased as compared to the control. Leaves of each treated and control plant showed substantial variations in color and temperature. However, maximum leaf temperature was recorded in a $225 \mathrm{mM} \mathrm{NaCl}$ treated
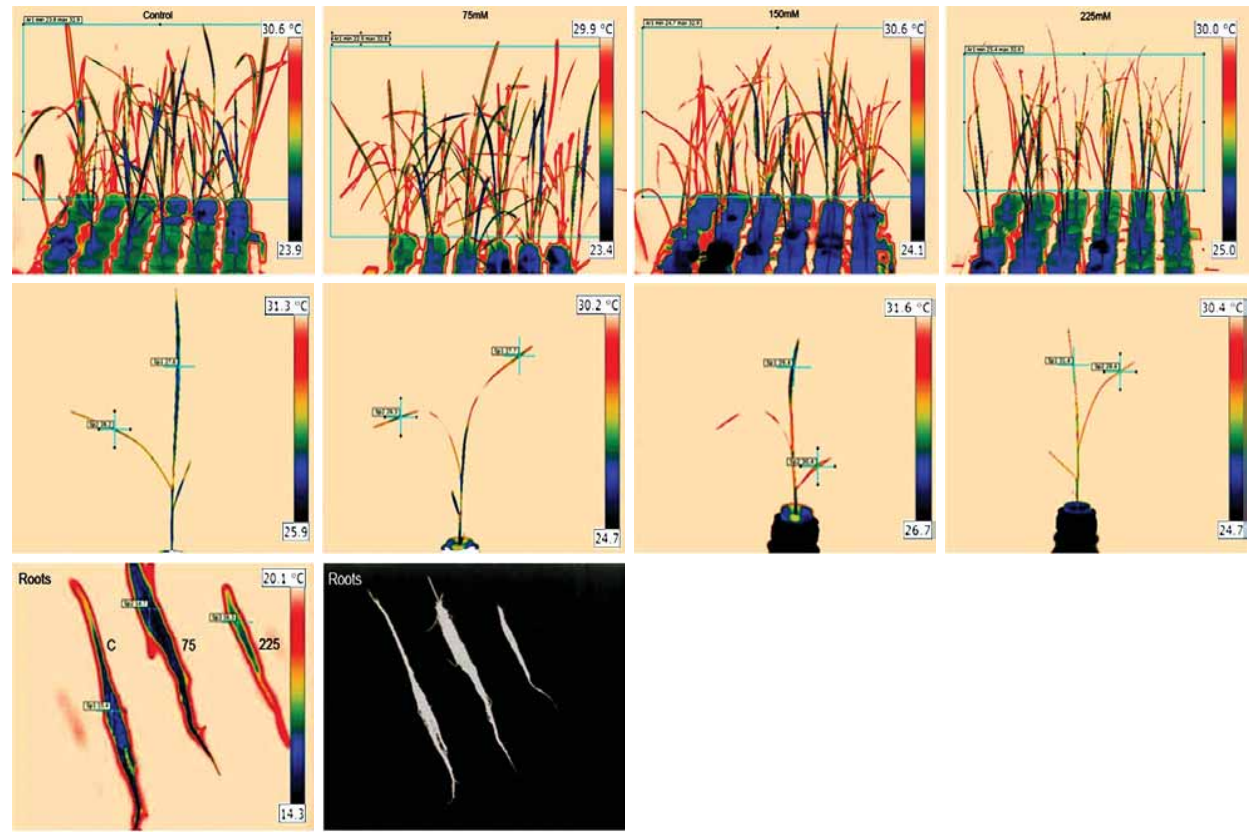

Fig. 1. Infrared images of plants treated with $\mathrm{NaCl}$ in the concentration range 0-225 mM, observed by a FLIR-SC-620 camera. Images were analyzed by ThermaCAM Researcher Pro 2.10 software. First row shows the whole plants set treated with salt in comparison to the control. Second row represents a single plant treated with same salt and control solutions. Third row shows the roots of treated and control plants. 
plant compared to control (Tab. 2). Likewise, the roots of salt stress plants also showed significant variations in color. Roots of highly salt stressed plants $(225 \mathrm{mM} \mathrm{NaCl})$ showed higher temperatures than the control plants. Root size was also greatly reduced in salt treated plants.

Tab. 2. Temperatures of salt-treated and control plants and leaves calculated based on the IR thermal images. Student t-test was done to compare control and salt treated samples. Different letters present significantly different values at $\mathrm{p}<0.05$.

\begin{tabular}{rlllllll}
\hline \multirow{2}{*}{$\mathrm{NaCl}$} & \multicolumn{3}{c}{ Plants temperature $\left({ }^{\circ} \mathrm{C}\right)$} & & \multicolumn{3}{c}{ Leaf temperature $\left({ }^{\circ} \mathrm{C}\right)$} \\
\cline { 2 - 3 } \cline { 6 - 8 } & Min & Max & Avg & & Min & Max & Avg \\
\hline Control & $23.8^{\mathrm{a}}$ & $32.9^{\mathrm{a}}$ & $28.4^{\mathrm{a}}$ & & $27.6^{\mathrm{a}}$ & $28.2^{\mathrm{a}}$ & $27.9^{\mathrm{a}}$ \\
$75 \mathrm{mM}$ & $22.9^{\mathrm{b}}$ & $32.8^{\mathrm{a}}$ & $27.9^{\mathrm{b}}$ & & $27.7^{\mathrm{a}}$ & $29.3^{\mathrm{b}}$ & $28.5^{\mathrm{b}}$ \\
$150 \mathrm{mM}$ & $25.1^{\mathrm{c}}$ & $33.7^{\mathrm{b}}$ & $29.4^{\mathrm{c}}$ & & $29.4^{\mathrm{b}}$ & $30.4^{\mathrm{c}}$ & $29.9^{\mathrm{c}}$ \\
$225 \mathrm{mM}$ & $26.1^{\mathrm{d}}$ & $32.8^{\mathrm{a}}$ & $29.5^{\mathrm{c}}$ & & $29.4^{\mathrm{b}}$ & $31.4^{\mathrm{d}}$ & $30.4^{\mathrm{d}}$ \\
\hline
\end{tabular}

Student t-test was done to compare control and salt treated samples. Similar alphabets are non-significantly differed at $\mathrm{p}<0.05$. Avg - average.

Performance index of salt treated and untreated plants were examined and were expressed on a graph (Fig. 2). Performance indices gradually declined due to salt stress, as compared to the control. The lowest performance index values as compared to the control

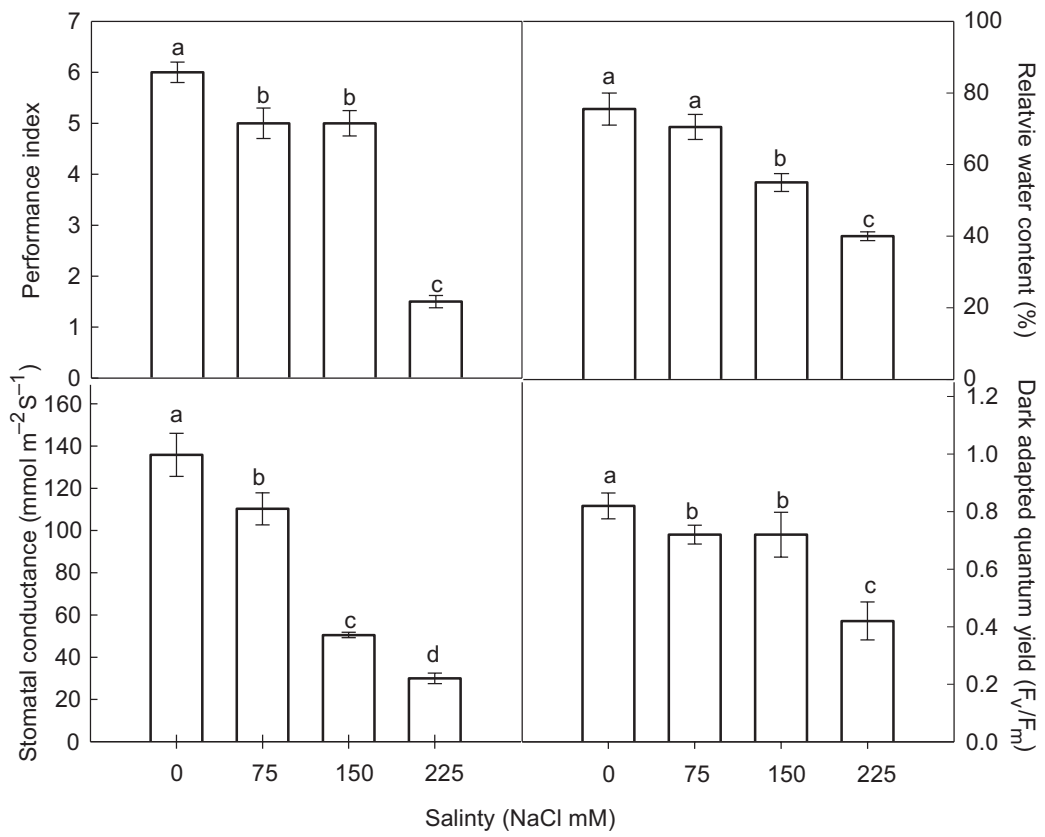

Fig. 2. Relative water content, stomatal conductance, performance index and dark-adapted quantum yield $\left(\mathrm{F}_{\mathrm{v}} / \mathrm{F}_{\mathrm{m}}\right)$ in saline-treated plants in comparison to the control. Values are mean $\pm \mathrm{SE}, \mathrm{n}=$ 4. Different letters represent statistically significant values $(\mathrm{p}<0.05)$. 
were found in a $225 \mathrm{mM} \mathrm{NaCl}$ treated plant. The relative water content as compared to the control plant decreased upon salt stress in a dose-dependent manner (Fig. 2). Maximum decrease in relative water content as compared to the control was found in $225 \mathrm{mM} \mathrm{NaCl}$ treated sample. Likewise, stomatal conductances in plants as compared to the control were significantly decreased in a salt-treated sample (Fig. 2). Moreover, the study showed that the decrease in stomatal conductance was related to salt concentrations resulting in a maximum decrease at $225 \mathrm{mM} \mathrm{NaCl}$ treatment. Similarly, dark-adapted quantum yield $\left(\mathrm{F}_{\mathrm{v}} / \mathrm{F}_{\mathrm{m}}\right)$ was reduced in a salt-treated plant. Maximum decrease as compared to the control was observed in a $225 \mathrm{mM}$-treated plant while decrease in quantum yield was somewhat similar and was non-significant in 75 and $150 \mathrm{mM}$ treated plants.

Correlations between the average IR image temperature pattern and physiological attributes like relative water content, stomatal conductance, performance index and dark-adapted quantum yield were significant (Fig. 3). Significant negative correlation was observed between average image temperature and relative water content $\left(R^{2}=-0.852\right)$ as well as stomatal conductance $\left(\mathrm{R}^{2}=-0.612\right)$ while correlation between plant temperature and performance index $\left(\mathrm{R}^{2}=-0.315\right)$ as well as dark-adapted quantum yield $\left(\mathrm{R}^{2}=-0.325\right)$ was not significant.

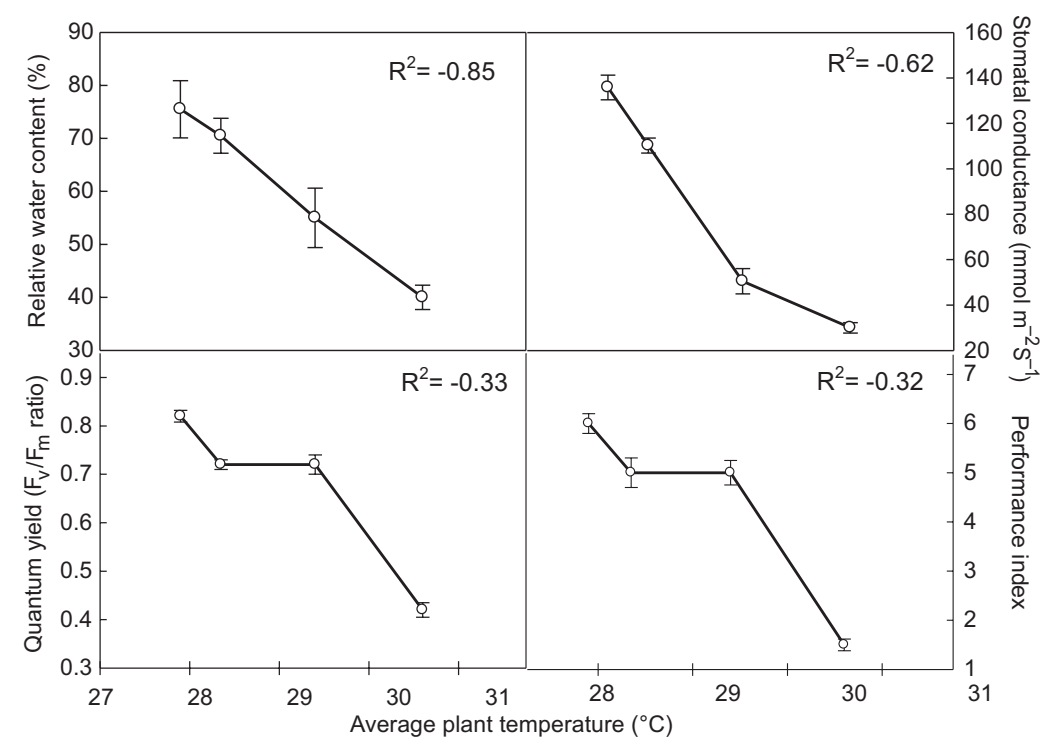

Fig. 3. Correlations between average plant temperature and relative water contents, stomatal conductance, performance index and dark-adapted quantum yield $\left(\mathrm{F}_{\mathrm{v}} / \mathrm{F}_{\mathrm{m}}\right)$ tested in saline and non-saline environment. $\mathrm{R}^{2}$ stands for linear regression values.

\section{Discussion}

Comparison and correlation between conventional and modern phenotyping of rice plants in salt stress environment were conducted. Conventional phenotyping provided physiological attributes like relative water content, stomatal conductance, dark-adapted quan- 
tum yield and performance index. A modern approach using an IR thermal camera provided thermal variations in plants upon salt stress. It was found that physiological attributes like relative water content and stomatal conductance were significantly correlated with IR thermal-image temperature. On the other hand, performance index and quantum yield were not significantly correlated with the result obtained by IR thermography. Among several parameters obtained from the chlorophyll fluorescence measurements, the dark-adapted quantum yield $\left(\mathrm{F}_{\mathrm{v}} / \mathrm{F}_{\mathrm{m}}\right)$ and the performance index were selected for the comparison between salt stress and unstressed plant. The reason for this choice was that the $\mathrm{F}_{\mathrm{v}} / \mathrm{F}_{\mathrm{m}}$ ratio is the most extensively used photosystem II (PSII) efficiency indicator. This parameter has been shown to correlate with a number of functional PSII complexes. Many studies have used this ratio as an indicator for stress tolerance or sensitivity (PENUELAS and BOADA 2003). Performance index was introduced to quantify the effects of environmental factors like chilling, heat, drought, chromate, ozone, or urban injuries to photosynthesis (HERMANS et al. 2003, DE RONDE et al. 2004, STRAUSS et al. 2006). In this study, neither parameter was significantly correlated with the result obtained by IR thermography. The reason behind this may be that IR sensing is based on heat generation of plant which is linked with water status rather than photosynthetic performance.

Stomatal conductance, relative water content and dark-adapted quantum yield, performance index are affected by salt stress and these physiological attributes are linked with the leaf temperature (MunNs et al. 2010). Generally, water loss from the leaf needs a substantial amount of energy to convert each molecule of water from liquid to vapor. This energy is then taken away from the leaf in the evaporating water for cooling purpose (JONES et al. 2009). Thus, for a given environmental or stress condition, leaf transpiration is an important determinant of leaf temperature. In the case of stress caused by either salt or drought, an immediate plant response is a reduction in transpiration to reduce water loss, and an increase in the leaf temperature (Woo et al. 2008, MunNS et al. 2010). Moreover, GARRITY and O' Toole (1994) have shown that IR thermography could be used to determine leaf and canopy temperature, although as an indirect estimation of plant water status. It is presumed that a direct and an indirect relationship between physiological parameters and IR images are based on the type and nature of stress, plants and research area. For instance, genotypes with a higher tolerance to stress uptake soil water efficiently by maintaining higher stomatal conductance and therefore can be identified as plants with cooler leaves (JoNES et al. 2009, BERGER et al. 2010, Lu et al. 2011). Further, SiRAULT et al. (2009) has suggested that leaf temperature is an indicator of stomatal conductance and it was increased with high salt concentration (MunNs et al. 2010). The ranking of the genotypes based on the growth study and thermal IR measurements was consistent (JAMES et al. 2008) and both have been successfully deployed in wheat breeding for both drought and heat screening (FISCHER et al. 1998, REYNOLDS et al. 1998, BRENNAN et al. 2007).

In this study, high salt concentration $(225 \mathrm{mM} \mathrm{NaCl})$ caused a substantial reduction in stomatal conduction and relative leaf water content and subsequently increased average plant leaf temperature. It was shown that dark-adapted quantum yield and IR images were non-significantly correlated. Hence, it could be stated that decrease in stomatal conductance and relative water content in leaf could generate more heat, causing leaf temperature to increase in a given leaf area. Leaf temperature is a proximate indicator of stomatal conductance and water status which are often analyzed with an IR sensor (SIRAULT et al. 2009, MunNs et al. 2010). Physiological attributes like stomatal conductance and IR images were found consistent in previous studies (JONES et al. 2009, MunNs et al. 2010). 
Dark-adapted quantum yield, $\mathrm{F}_{\mathrm{v}} / \mathrm{F}_{\mathrm{m}}$ (a measure of the intrinsic photochemical efficiency of light harvesting in photosystem II) is the most easily measured and commonly used fluorescence parameter in the stress studies (BAKER et al. 2008). Photosynthesis ability of a plant under stress condition is attributed to stomata factors, which not only regulate leaf water content but also maintain carbon dioxide concentration inside the leaf (BROUGNOLY and Lauteri 1991, Tourneux and Peltier 1995, Khan and Panda 2008, Siddiqui et al. 2008). Water status in a plant is highly sensitive to salinity and therefore it is dominant in determining plant responses to stress (STEPIEN and KLOBUs 2006). Dark-adapted quantum yield responses to salt or drought stress environment are rather slow and can be detectable in a large tray experiment using very small seedlings (Woo et al. 2008, JANSEN et al. 2009). Since this experiment was carried out using small trays, it was presumed that dark-adapted quantum yield may not produce significant change in leaf temperature and thus it could not be detected by IR thermal images sensing. Therefore, based on the working principal of the IR camera, it could be suggested that IR may not be related to the photosynthesis performance of a plant under saline environment. Meanwhile, plant temperature allows the indication of the degree of stress in a crop on the basis of relative water content and stomatal conductance. In stress, plant temperature and water stress are perhaps linked to soil water availability, leaf water potential, and stomatal conductance. IR thermography was proved to be related to soil- and plant-based measures of water stress. It was also observed that IR thermography can be potentially used for identifying the differences between genotypes and single crop in variable plant irrigation and stress environment (RomANO et al. 2011, ZIA et al. 2011). However, high technology utilization in field experiment needs to be developed in order to identify the best protocol to optimize the data accuracy.

\section{Conclusion}

Correlation analysis between conventional and modern phenotyping showed that plant or leaf temperature variation could be a useful tool to identify stress tolerant physiotype/genotype in the stress environment. A modern analysis performed by highly sensitive IR camera (IR thermography techniques) may be less time consuming, non-destructive and cover a larger scale.

\section{Acknowledgments}

This work was supported by a grant from the Next-Generation Bio-Green 21 Program (No. PJ009008), Rural Development Administration, Suwon, Republic of Korea. F. Z. S. is thankful to Department of Botany, University of Karachi, Pakistan for enabling a post-doctoral study period abroad.

\section{References}

BAKER, N. R., 2008: Chlorophyll fluorescence: a probe of photosynthesis in vivo. Annual Review of Plant Biology 59, 89-113.

Berger, B., PAREnt, B., Tester, M., 2010: High-throughput shoot imaging to study drought response. Journal of Experimental Botany 61, 3519-3528.

Brennan, J. P., Condon, A. G., van-Ginkel, M., Reynolds, M. P., 2007: An economic assessment of the use of physiological selection for stomatal aperture-related traits in the CIMMYT wheat breeding program. Journal of Agricultural Sciences 145, 187-194. 
BRUGNOLY, E., LAUTERI, M., 1991: Effects of salinity on stomatal conductance, photosynthetic capacity, and carbon isotope discrimination of salt tolerant (Gossypium hirsutum L.) and salt sensitive (Phaseolus vulgaris L.) C3 non-halophytes. Plant Physiology 95, 628-635.

Burke, E. J., Brown, S. J., Christidis, N., 2006: Modeling the recent evolution of global drought and projections for the twenty-first century with the Hadley Centre climate model. Journal of Hydrometeorology 7, 1113-1125.

Collins, M., Fuentes, S., BARlow, E. W. R., 2010: Partial root zone drying and deficit irrigation increase stomatal sensitivity to vapour pressure deficit in anisohydric grapevines. Functional Plant Biology 37, 128-138.

Davies, W. J., Kudoyarova, G., Hartung, W., 2005: Long-distance ABA signaling and its relation to other signaling pathways in the detection of soil drying and the mediation of the plant's response to drought. Journal of Plant Growth Regulators 24, 285-295.

de Ronde, J. A., Cress, W. A., Kruger, G. H. J., Strasser, R. J., van Staden, J., 2004: Photosynthetic response of transgenic soybean plants, containing an Arabidopsis P5CR gene, during heat and drought stress. Journal of Plant Physiology 161, 1211-1224.

Fischer, R. A., Rees, D., SAyre, K. D., Lu, Z. M., Cordon, A. G., SAAvedra, A. L., 1998: Wheat yield progress associated with higher stomatal conductance and photosynthetic rate and cooler canopies. Crop Science 38, 1467-1475.

GARrity, D. P., O’ ToOLE, J. C., 1994: Screening rice for drought resistance at the reproductive phase. Field Crop Research 39, 99-110.

Hermans, C., Smeyers, M., Rodriguez, R. M., Eyletters, M., Strasser, R., Dehaye, J. P., 2003: Quality assessment of urban's trees: a comparative study of physiological characterization, airborne imaging and on site fluorescence monitoring by the OJIP test. Journal of Plant Physiology 160, 81-90.

James Ra, V. O. N., Caemmerer, S., Condon, A. G., Zwart, A. B., Munns, R., 2008: Genetic variation in tolerance to the osmotic stress component of salinity stress in durum wheat. Functional Plant Biology 35, 111-123.

Jansen, M., Gilmer, F., Biskup, B., Nagel, K. A., Rascher, U., Fischbach, A., Briem, S., Dreissen, G., Tittmann, S., Braun, S., 2009: Simultaneous measurement of leaf growth and chlorophyll fluorescence via GROWSCREEN FLUORO allows detection of stress tolerance in Arabidopsis thaliana and other rosette plants. Functional Plant Biology 36, 902-914.

Jones, H. G., Serraj, R., Loveys, B. R., Xiong, L., Wheaton, A., Price, A. H., 2009: Thermal infrared imaging of crop canopies for the remote diagnosis and quantification of plant responses to water stress in the field. Functional Plant Biology 36, 978-989.

Khan, M. H., PANDA, S. K., 2008: Alterations in root lipid peroxidation and antioxidative responses in two rice cultivars under $\mathrm{NaCl}$-salinity stress. Acta Physyologiae Plantarum $30,91-89$.

Lu, Y., Hao, Z., Xie, C., Crossa, J., Araus, J. L., Gao, S., Vivek, B. S., Magorokosho, C., Mugo, S., Makumbi, D., Taba, S., Pan, G., Li, X., Rong, T., Zhang, S., XuA, Y., 2011: Large-scale screening for maize drought resistance using multiple selection criteria evaluated under water stressed and well-watered environments. Field Crop Research $124,37-45$. 
MAXwell, K., Johnson, G. N., 2000: Chlorophyll fluorescence - a practical guide. Journal of Experimental Botany 51, 659-668.

Merlot, S., Mustilli, A. C., Genty, B., North, H., Lefebvre, V., Sotta, B., Vavasseur, A., GiRAudAT, J., 2002: Use of infrared thermal imaging to isolate Arabidopsis mutants defective in stomatal regulation. The Plant Journal 30, 601-609.

Munns, R., James, R. A., Sirault, X. R. R., Furbank, R. T., Jones, H. G., 2010: New phenotyping methods for screening wheat and barley for beneficial responses to water deficit. Journal of Experimental Botany 61, 3499-3507.

Penuelas, J., Boada, M., 2003: A global change-induced biome shift in the Montseny mountains (NE Spain). Global Change Biology 9, 131-140.

Reynolds, M. P., Singh, R. P., Ibrahim, A., Ageeb, O. A. A., Larque-SaAvenra, A., QUICK, J. S., 1998: Evaluating physiological tools to complement empirical selection for wheat in warm environments. Euphytica 100, 84-95.

Richards, R. A., Rebetzke, G. J., Watt, M., Condon, A. G., Spielmeyer, W., Dolferus, R., 2010: Breeding for improved water productivity in temperature cereals: phenotyping, quantitative trait loci, markers and the selection environments. Functional Plant Biology 37, 85-97.

Romano, G., Zia, S., Spreer, W., Sanchez, C., Cairns, J., Araus, J. L., Muller, J., 2011: Use of thermography for screening genotypic water stress adaptation in tropical maize. Computer and Electronic in Agriculture 79, 61-74.

SidDIQUi, Z. S., 2013: Effects of double stress on antioxidant enzyme activity in Vigna radiata (L.) Wilczek. Acta Botanica Croatica 72, 145-156.

Siddiqui, Z. S., Khan, M. A., Beomgi, K., Huang, J-S., Kwon, T. R., 2008: Physiological response of Brassica napus genotypes in combined stress. Plant Stress 2, 78-83.

Strauss, A. J., Krüger, G. H. J., Strasser, R. J., van Heerden, P. D. R. 2006: Ranking of dark chilling tolerance in soybean genotypes probed by the chlorophyll a fluorescence transient O-J-I-P. Environmental and Experimental Botany 56,147-157.

Sirault, X. R. R., James, R. A., Furbank, R. T., 2009: A new screening method for osmotic component of salinity tolerance in cereals using infrared thermography. Functional Plant Biology 36, 970-977.

Stepien, P., Klobus, G., 2006: Water relations and photosynthesi in Cucumis sativus L. leaves under salt stress. Biologia Plantarum 50, 610-616.

Tourneux, C., Peltier, G., 1995: Effect of water deficit on the photosynthetic oxygen exchange measured using $18 \mathrm{O} 2$ and mass spectrometry in Solanum tuberosum leaf disks. Planta 195, 570-577.

Woo, N., BADger, M. R., Pogson, B., 2008: A rapid non-invasive procedure for quantitative assessment of drought survival using chlorophyll fluorescence. Plant Methods 4, 27.

Zia, S., Spohrer, K., Wenyong, D., Spreer, W., Romano, G., Xiongkui, H., Mller, J., 2011: Monitoring physiological responses to water stress in two maize varieties by infrared thermography. International Journal of Agricultural and Biological Engineering 4, 7-15. 